\title{
Technology of metal-polymer form-building parts of compression molds
}

\author{
Nickolai Sergeevich Lubimyi \\ Department of mechanical engineering \\ Belgorod State Technological University named after \\ V.G. Shoukhov \\ BSTU named after V. G. Shoukhov \\ 308012, Kostukov St., 46 \\ Belgorod, Russia \\ Pershin26@yandex.ru \\ Irina Alexandrovna Teterina \\ Department of mechanical engineering \\ Belgorod State Technological University named after \\ V.G. Shoukhov \\ BSTU named after V. G. Shoukhov \\ 308012, Kostukov St., 46 \\ Belgorod, Russia \\ irinochka1611@rambler.ru
}

\begin{abstract}
The article describes the technology of combined metal-metal-polymer molds to cast plastic products. The economic feasibility of this technology is confirmed by comparing the processing layouts to obtain a mold for the same product, machining and using a metal-polymer as a forming surface material. The values of the main technological time and the prime cost of the mold-forming surface manufacturing by the metal-polymer forming are obtained. The work describes the technology of metal-polymer molding parts with the specifics of the mold closing plane finishing machining and features to obtain product models by layer-by-layer growing with 3D printers. The area ща efficient use of the described technology is determined. The developed technology was tested while manufacturing an "asterisk" product, for which a metal-polymer mold was produced. In the article, there is a link to the video where the test of an "asterisk" product mold is demonstrated.
\end{abstract}

Keywords-mold; metal-polymer; form-forming; cost; technological process; $3 D$ printing.

\section{INTRODUCTION}

The mass production of plastic disposable items requires the use of the special-purpose automated equipment and machine-tool attachments specific to each item - molds. The machine-tool attachments are designed and manufactured for each item. The cost of this design and manufacture makes a considerable part of the price in the item pre-production engineering. As such, the mass production of one item is set up as the switch to every new item, is very cost consuming and increases its price. The authors analyze the production process of mold form-building parts that are the most essential and consumptive element of the machine-tool attachment.

\author{
Mihail Sergeevich Chepchurov \\ Department of Mechanical Engineering \\ Belgorod State Technological University named after \\ V.G. Shoukhov \\ BSTU named after V. G. Shoukhov \\ 308012, Kostukov St., 46 \\ Belgorod, Russia \\ avtpost@mail.ru \\ Evgenii Alexandrovich Yakovlev \\ Department of roads and railways \\ Belgorod State Technological University named after \\ V.G. Shoukhov \\ BSTU named after V. G. Shoukhov \\ 308012, Kostukov St., 46 \\ Belgorod, Russia
}

As an example, the authors used the production documents of the "Medal" form-building mold that was provided by the plastic product manufacturing enterprise. The available data were analyzed and presented as a diagram in Fig.1.

The process has a linear structure, as one product is transmitted in succession from one equipment to another. The process is completed by the cavity broaching to get products on the EDM (electrical discharge machining) machine. An obtained product does not require any additional finishing treatment as processing conditions provide the necessary surface roughness.

The time spent to manufacture the form-building mold can be calculated as:

$$
T_{o}=\max \quad m_{j=1}^{m} T_{j}+\underset{k=1}{p} T_{k}+\underset{i=1}{n} T_{i}
$$

where:

$n$ - number of operations before the electrical discharge machining; $m$ - number of operations since the electrical discharge machining; - number of operations to manufacture the electrode-tool; - operation number before the electrical discharge machining;-- operation number since the start of the electrical discharge machining; - operation number to manufacture the electrode-tool; $T$ - operation time, min. 


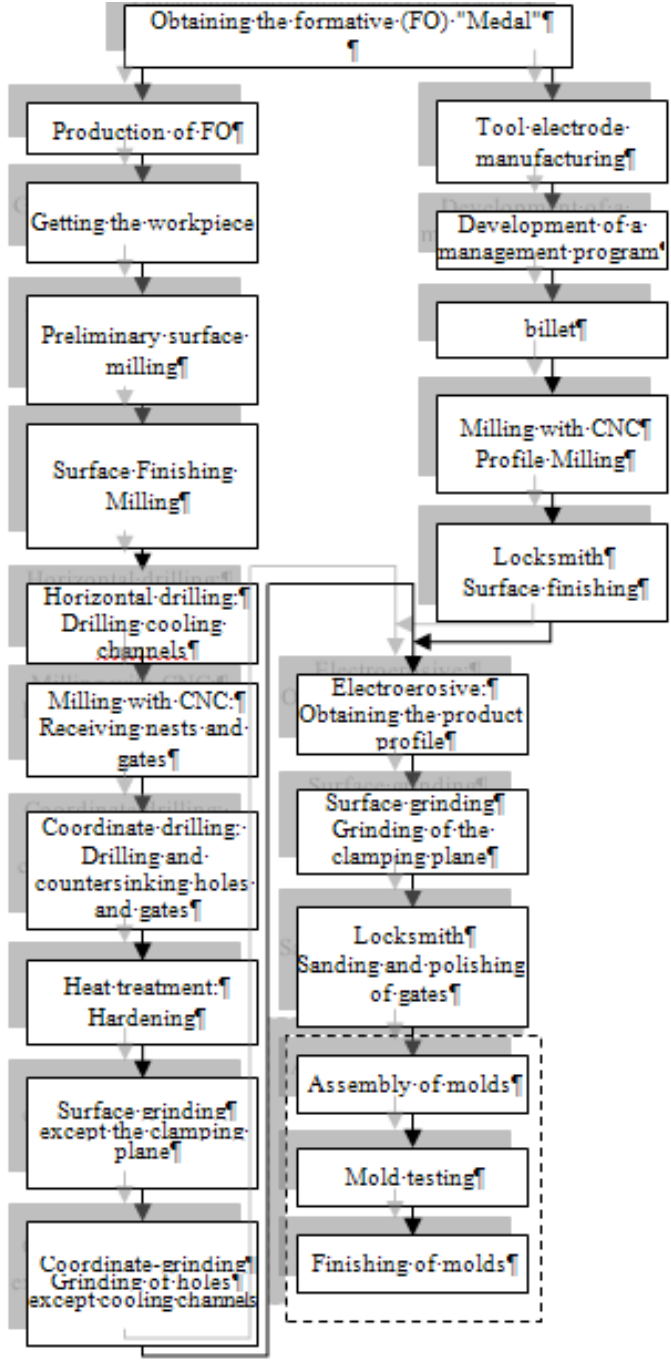

Fig. 1. Diagram of the production process to obtain the "Medal" formbuilding mold

The manufacturing cost of the form-building part includes contributions under the formula

$$
\begin{array}{r}
C=C_{m p}+C_{b c p}+C_{e p}+C_{m e}+C_{b c e}+C_{e e}+S_{p}+S_{e} \\
1+C C+C_{0},
\end{array} .
$$

where:

$C_{m p}$ - form-building part material; $C_{b c p}$ - by-product cost for form-building part; $C_{e p}-$ energy cost consumed to manufacture the form-building part;

$C_{m e}$ - material cost to manufacture the electrode-tool; $C_{b c e}$ - by-product cost to manufacture the electrode-tool; $C_{e e}-$ energy cost to manufacture the electrode-tool; $S_{p}$ - core and non-operational personnel salary to manufacture the formbuilding part; $S_{e}$ - core and non-operational personnel salary to manufacture the electrode-tool; $C C$ - fringe benefit expense coefficient $(=/ 100, \quad$ - fringe benefit expenses in $\%) ; C_{0}$ operating costs to manufacture the form-building part.

According to the documents provided by the plastic product manufacturing enterprise, the form-building part production time is 12 days; the time expenditure - 110 standard work hours; shop floor cost - 20300 rub.

It should be borne in mind that the mold, the form-building part that is used in the mass production $[1,2]$ and its cost are included in the product price. Thus, according to the manufacturing data book, the product that is produced in the mold can have a competitive price if the consignment is not less than 10000 items. It does not allow manufacturing the range of items at lower consignments. Therefore, the cost structure (Fig. 2) shows the manufacturing cost of the electrode-tool and the effective surface manufacture cost of the form-building part

According to Fig. 2, the form-building part material cost is included in the preparatory work cost. The form-building part material is $\mathrm{X} 46 \mathrm{Cr} 13$ - 1.4034 for EN 10088-3:2005. The main part of the manufacturing cost of the form-building part is the electrode-tool fabrication and electrical discharge machining cost - 9700 that is $48 \%$ of the form-building part. The time expenditure to manufacture the electrode-tool is 12 standard work hours; the electrical discharge machining - 24 standard work hours; total $-32 \%$. Therefore, the time expenditure for EDMing and electrode-tool production -4 shifts or 2 days at two-shift operation $-17 \%$.

Sorting out the priorities, it is possible to define the optimization objective - conversion cost reduction of the mold form-building parts as the reduction of the EDMing time by $50 \%$ allows to reduce the conversion cost of the form-building part by $24 \%$.

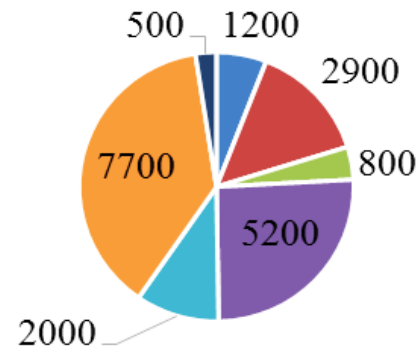

$$
\begin{aligned}
& \text { - Procurement work. Preliminary processing } \\
& \text { - Finishing. Coordinate-drilling, coordinate-milling } \\
& \text { with numerical control } \\
& \text { " Heat treatment } \\
& \text { - Surface grinding, intragrinding } \\
& \text { - Manufacture of an electrode-tool } \\
& \text { - Obtaining work surfaces } \\
& \text { - Finishing of working surfaces }
\end{aligned}
$$

Fig. 2. Diagram of the production process cost to obtain the "Medal" formbuilding mold (according to the manufacturer)

The reduction of the EDMing time by $50 \%$ will allow cutting the production time by 1 day. If the practical time is 10 days, this reduction is not significant and is within the 
deadline of the article production. Therefore, the retooling objective is to reduce the conversion cost of form-building parts.

\section{METHODS}

Before setting the research objectives, the authors carried out some experiments on the metal-polymer compound application to manufacture the form-building molds. One of the first products obtained in such mold (hook) by the authors, is shown in Fig.3.

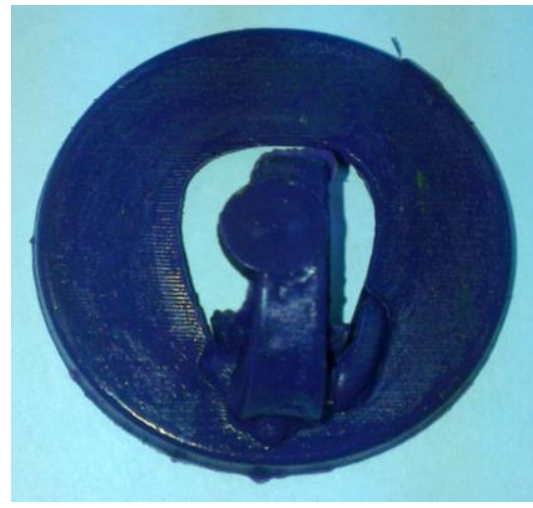

Fig.3. "Hook" product obtained in the metal-polymer mold

To solve this engineering problem, in the form building plate of the mold, half the cavity is made of metal-polymer, and in the top mold half (hob) the cavity is made of metalpolymer. The execution of several dozens of cycles to manufacture products led to the necessity to design a new model of the operating process with the metal-polymer use.

Analysis revealed that there are some elements in the form-building part that require the high strength and wearresistance. These elements are guide pin eyelets and ejector pad eyelets. These structural components have a simple geometric shape and do not require high expenses for their execution. The operating surface of the mold form-building surface is time-, money- and energy-consuming and the material cost to manufacture the electrode-tool is significant. The model based on the operating process time of the metalpolymer form-building part is:

$$
T_{o}={ }_{i=1}^{n} T_{i}+\stackrel{s}{l=1} T_{l} \text {, }
$$

where,

- operating time to produce the metal-polymer formbuilding part; $l$-operation number to manufacture the metalpolymer form-building part; $s$ - number of operations to manufacture the metal-polymer form-building part.

The operating process diagram is shown in Fig.4. This diagram is different from that in Fig.1 by the fact that it consists in half of the technical operations to manufacture the metal-polymer form-building part surface.

If we draw an analogy with Fig. 1, the electrode-tool preparation corresponds to the $3 \mathrm{D}$ model. The authors do not refer to other methods for the model production on purpose, as other methods are far more expensive than the used polymer $3 \mathrm{D}$ printing. This is the reason why in formula 3 there is no maximum set up time selection and 3D model printing as these values can be two times lower, in other words, the 3D printing process is shorter.

The metal-polymer compound curing takes the most considerable time, but this operation is less resource consuming.

Therefore, the expenses to manufacture the metal-polymer form-building part can be expressed as:

$$
C_{\mathrm{o}}^{M}=C_{m p}+C_{m}+C_{e}+C_{e f}
$$

where,

$C_{m p}$ - preparation cost of metal-polymer form-building part manufacturing; $C_{m}-$ model manufacturing cost; $C_{e}$ metal-polymer surface manufacturing $\operatorname{cost} ; C_{e f}$, - engineering follow up cost.

So, it turned out that:

$$
C_{0}^{M}<C_{\text {o }}
$$

Let us analyze the features of metal-polymer equipment manufacturing. The use of this method supposes the application of additive layer-by-layer master-model manufacturing. This master-model is made of the specialpurpose plastic - PLA (polylactide) or $A B S$ (acrylonitrile butadiene styrene) [3].

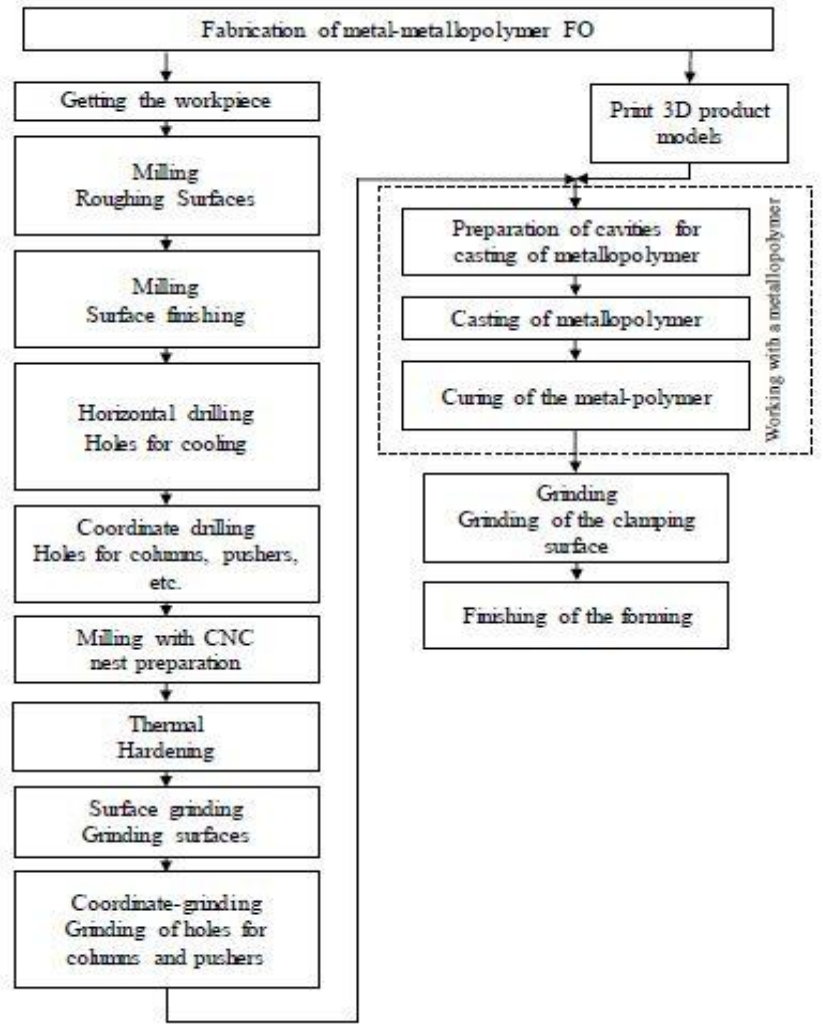

Fig. 4. Diagram of the production process of the metal-polymer equipment manufacturing 
The first material is biodegradable; the second one is very durable in comparison with other materials for 3D printing. However, the essential requirement to the polymer model is not only its durability, but also the accuracy in size and the geometric relationship. It is known that an unequal cooling at printing can cause the model deformation that makes it unsuitable to manufacture the metal-polymer equipment. In other words, if the model is produced by the layer-by-layer method, it is worth to provide the printing conditions and modes that eliminate the drawbacks.

As part of the study, it was specified that printing of the $600-\mathrm{mm}^{2}$ model requires not less than 4 hours and the model price is composed of the equipment operating cost, wear and tear, material and energy cost. ABS plastic consumption is not higher than $5 \mathrm{~g}$ as the model has a honeycomb structure not only for material saving, but to reduce the model deformation.

Taking the "star" model printing as an example, it was specified that if you use a more expensive 3D printing method based on SLA-technology and a FullCure720 photopolymer, it is possible to obtain the model that corresponds to the sixth class of the size accuracy and the geometric relationship. The model roughness degree corresponds to Ra $0.63-0.32 \mu \mathrm{m}$. It is not advisable to use the lubricant parting compounds when the model pattern is generated in the metal-polymer compound. The lubricant parting compounds should not be used due to their adhesion to metalpolymers that lead to the change of mechanical-and-physical properties of the surface coats of the cured metal-polymer compound. As such, it is necessary to get gloss models to remove them easily from the cured metalpolymer. The received parameters of the model at SLAbased printing are the most optimal as they have the best roughness and durability parameters among all known 3D printing methods. FullCure720 parameters are shown in table 1.

TABLE I. FULLCURE720 PARAMETERS

\begin{tabular}{|c|c|c|}
\hline Parameter & Test technique & Value \\
\hline Breaking tenancy & D638-03 & $50-65 \mathrm{MPa}$ \\
\hline Breaking extension & D638-05 & $15-25 \%$ \\
\hline Elasticity coefficient & D638-04 & $2000-3000 \mathrm{MPa}$ \\
\hline Bending strength & D790-03 & $80-110 \mathrm{MPa}$ \\
\hline Flexure modulus & D790-04 & $2700-3300 \mathrm{MPa}$ \\
\hline HDT 0,45MPa & D648-06 & $45-50^{\circ} \mathrm{C}$ \\
\hline HDT 1,82MPa & D648-07 & $45-50^{\circ} \mathrm{C}$ \\
\hline Izod impact strength & D256-06 & $20-30 \mathrm{~J} / \mathrm{m}$ \\
\hline Water absorption & D-570-98 for $24 \mathrm{~h}$. & $1.5-2.2 \%$ \\
\hline Tg & DMA. E & $48-50^{\circ} \mathrm{C}$ \\
\hline Shore hardness (D) & Scale D & $83-86$ \\
\hline Rockwell hardness & Scale M & $73-76$ \\
\hline Density & D792 & $1.18-1.19 \mathrm{~g} / \mathrm{sm}^{3}$ \\
\hline Irreversible ash content & USP281 & $0.01-0.02 \%$ \\
\hline
\end{tabular}

The technology of obtaining the form-building part from the metal-polymer compound includes the preparation process and its embedding by the metalpolymer [4] as it is suggested by the material manufacturer, the cavity forming or embedding and material curing.

This operation has a much lower labor cost as well as energy and operation cost. The curing operation takes not less than 24 hours, according to the metalpolymer manufacturer data, and that does not allow fulfilling the urgent production of the form-building part surface compared to other types of dressing. In other words, at the urgent production it is worth to compare the surface manufacture time from the metalpolymer and the time of EDMing and high-speed milling.

If the accuracy and roughness of the operating metalpolymer form-building part is determined by the model quality characteristics, metalpolymer parameters and quality, the accuracy of the metalpolymer manufacturer recommendation fulfillment [4], the manufacture of the form-building part clamping surface requires the system approach as in [5]. With that in mind, it is necessary to provide the accuracy in the form-building part surface fulfilled according to the 6-7 accuracy degree, the roughness is not higher than $0,80 \mu \mathrm{m}$ according to [6], the flatness tolerance corresponds to the $6^{\text {th }}$ accuracy degree, the parallelity tolerance is of the $6^{\text {th }}$ accuracy degree. Therefore, let us use the same methods of the surface forming as for the operating process shown in Fig.l, and the same equipment, for example, a surface-grinding machine. Herewith, if the form-building part is made of metal, it is easy to determine the machining time and cost [7]. For the metalpolymer form-building part, this process is undetermined as there are two materials with different parameters that are machined together, but, at the same time, it is necessary to provide the equal parameters of accuracy and roughness of the achieved surfaces. The parameter of the critical roughness restriction for $\mathrm{X} 46 \mathrm{Cr} 13$ hard steel - 1.4034 for EN 100883:2005 and for the diene-based metalpolymer is completely different.

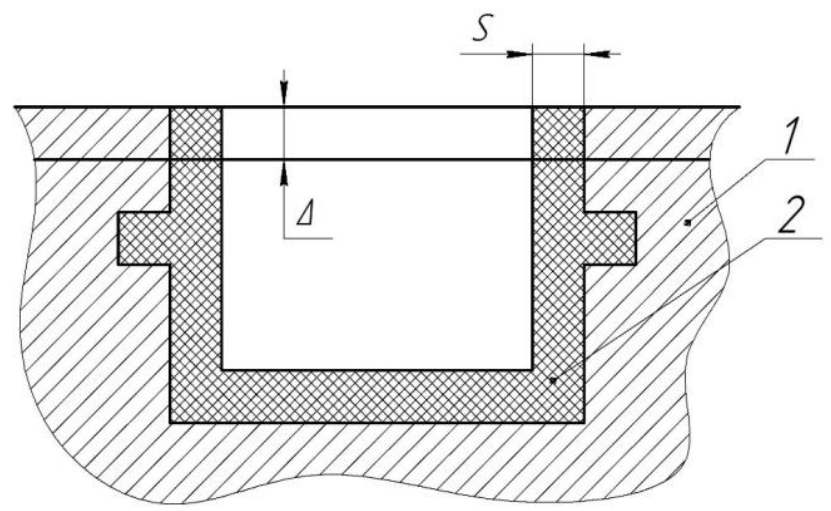

Fig. 5. Diagram of the metal-polymer form-building part cavity. 1 - metal part; 2 - metal-polymer part

Hence, according to the metal and metalpolymer layout diagram shown in Fig.5, it is necessary to use the modes that are effective for metals and metalpolymers.

The $\Delta$ stock removal consists of two materials. The size of the metal-polymer component $S$ can change in terms of the cavity design. Anyway, when the stock is removed, the tool moves from one material to another.

\section{DISCUSSIONS}

Comparative analysis of the form-building part manufacture allowed the authors to suggest their own manufacturing method. 
The developed technology of metal-polymer form-building surfaces of molds presents the layer-by-layer 3D model printing [8], its placement in the mold half with the metalpolymer embedding and curing. The mold half is a metal plate with the cavity for the metal-polymer form-building part, air gates, cooling ducts, a sprue bush, centering holes. The metalpolymer curing takes place in the vacuum environment for 3 hours.

This technology is shown in Fig. 6.a, Fig. 6.b and supposes the following sequence: 3D printer grows layer-bylayer, pattern half 7 that is restricted by closing joint 6 . Then, metal plate 1 with sprue bush 3 , air gates 4 , cooling ducts 5 and centering holes 9 is produced. Metal plate 1 has a cavity to embed the liquid metalpolymer. Pattern half 7 is installed by closing joint 6 on principal plane 8 with locating dowels. It was identified [9] that the parting compounds should not be used to treat the master-model. Then, metal plate 1 is set to principal plane 8 at the top of pattern half 7 with the closing joint 6 . Metal plate 1 is centered against principal plane 8 by centering holes 9 and locating dowels of principal plane 8 . After that, the liquid metal-polymer composition with an aluminum filler that has a high thermal conductivity is prepared. The prepared liquid metal-polymer composition is poured to metal plate 1 cavity through air gates 4 . Sprue bush 3 is preliminary plugged from the liquid metal-polymer entering (for instance, by plasticine). Metal plate 1 with pattern half 7 set on principal plane 8 and embedded by the liquid metal-polymer is put to the vacuum environment to remove gaseous impurities from the liquid metalpolymer. These impurities influence the porosity and homogeneity of the cured metalpolymer [9] and, as a consequence, the thermal conductivity [10]. When the metalpolymer is cured, pattern half 7 should be pulled out within 3 hours. The generated mark of pattern half 7 in the cured metalpolymer is metalpolymer form-building surface 2 of the mold matrix.

Fig. 6.a shows the mold matrix that consists of metal plate 1 with the cavity for metal-polymer form-building part 2, sprue bush 3, air gates 4 and cooling ducts 5. Sprue bush 3 and air gate 4 axis are perpendicular to closing joint 6 . Metal plate 1 is placed over master-model half 7 . Closing joint 6 is close to principal plane 8 . Metal plate 1 is centered at principal plane 8 by centering holes 9 .

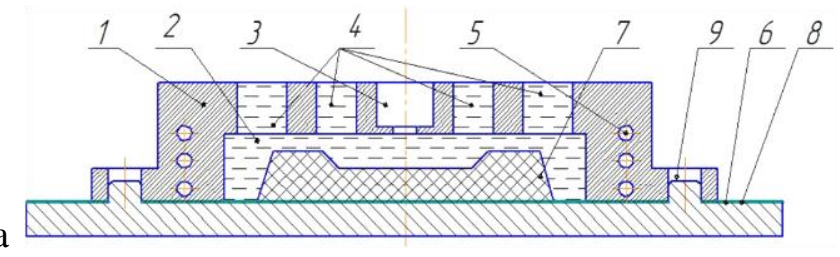

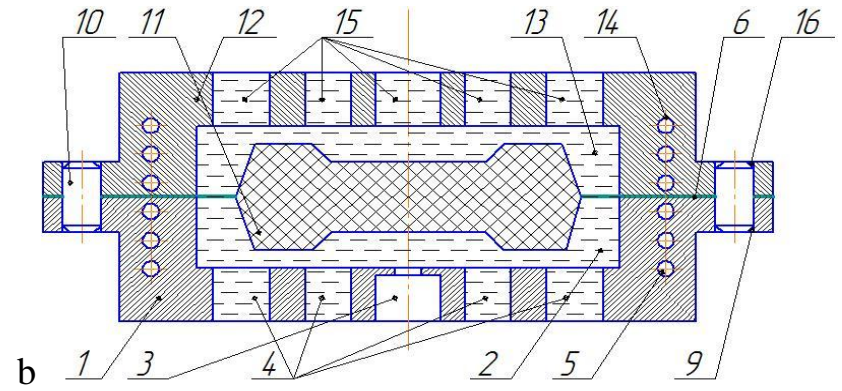

Fig. 6. Metal-polymer form-building part manufacture: $a$ - mold matrix; $b-$ mold matrix and core as an assembly

Fig. 6.b shows the mold matrix and core as an assembly that are centered by centering pins 10 . Model 11 is placed at the mold cavity. The mold core consists of metal plate 12 with metal-polymer form-building part cavity 13, cooling ducts 14 , air gates 15 , the axis of which are perpendicular to closing joint 6 and centering holes 16 .

Then, metal plate 1 is reversed and model 11 is placed over in obtained metal-polymer form-building surface 2 . Closing joint 6 of this model is placed to the matrix. In addition, it is necessary to place metal plate 12 that was manufactured in advance and has a cavity to pour the liquid metalpolymer, air gates 15, cooling ducts 14 and centering holes 16. Metal plate 12 is centered against the mold matrix by centering pins 10 and centering holes 9 and 16. After that, the liquid metalpolymer is poured to metal plate cavity 12 through air gates 15. Two metal plates 1 and 12 as an assembly with model 11 inside and the liquid metalpolymer poured to metal plate cavity 12 are placed to the vacuum environment where the metalpolymer is cured for 3 hours. When the metalpolymer is cured, two metal plates 1 and 12 are separated, and the model 11 is removed. The generated mark of model 11 in the cured metal-polymer of metal plate 12 is metal-polymer form-building surface 13 , and metal plate 12 itself with the cured metalpolymer is the mold core.

This technology supposes the increase in the pattern half strength limit. It can be achieved if metal plates 1 and 12 are used as pattern halves and play the role of the mold matrix and core metal frame. They take efforts made by the injectionmolding machine. The 3-hour curing in the vacuum environment allows to avoid the porosity of the cured metalpolymer and to improve its macrostructure and the mold wear-resistance.

The mold changeover process simplification for other products and the decrease in production cost are achieved by the fact that metal plates 1 and 12 with some structural eyelets can be reused for other products when metal-polymer formbuilding surfaces 2 and 13 are removed. The vacuum environment use during the curing process simplifies the process of cavity and hold-down groove pouring of metal plates 1 and 12 by the liquid metalpolymer.

The "Star" product manufacture in the mold with the metal-polymer form-building part produced by the aforementioned technology is presented here: https://yadi.sk/i/yyBBiQmwsVLHL. 


\section{CONCLUSION}

An adequate analysis with the estimated prime cost and operating process of the mold form-building part manufacture allowed the authors to develop their own technology to produce the similar products. The science-based, architectural and technological solution permitted to set an objective and to solve the problem of the product manufacture from composite materials that have the required mechanic and temperature parameters. The wear-resistance should be sufficient for medium batch and full-scale production.

\section{Acknowledgments}

The work was carried out within the framework of the agreement on granting subsidy No. 14.577.21.0193 of October 27, 2015, the theme: "Development of a robotic complex to implement the full-scale additive technologies of innovative materials, composites and structures". The unique identifier is PNIER RFMEFI57715X0193. The equipment was provided by High Technology Center at BSTU named after V.G. Shoukhov.

\section{References}

[1] M. Bichler, "Plastic parts - cast without defects," Heidelberg: Tsechner, Speyer, 1999, p. 112.

[2] G. Menges, V. Mikaeli, P. Moren, "How to make injection molds," $\mathrm{SPb}$.: The profession, 2007. p. 614.

[3] O.E. Babkin, "3D-prototyping: technologies, equipment, materials," SPb., 2013, p. 97.

[4] "Mini-catalog of chemistry WEICON," Moscow: Publishing house "Office UMP", 2013, p. 20.

[5] N.S. Lubimyi, M.S. Cheptchurov, I.A. Teterina, "Treatment of a combined metal-metal-polymer flat surface of a mold part," Bulletin of BSTU. V.G. Shukhov, Vol. 6, pp. 119-123, 2017.

[6] State Standard 27358-87, "Molds for the manufacture of plastic products. General specifications," Moscow, Standartov Publ., 2004, p.16.

[7] S.P. Korchak, "Productivity of grinding process of steel parts," Moscow. Mechanical Engineering, 1974, p. 280.

[8] T.A. Gorshkova, P.M. Kulandin, "Possibilities of modern 3D printing. Social and technical services: problems and ways of development," Collection of articles of the All-Russian Scientific and Practical Conference, 2015, pp. 148-150.

[9] N.S. Lubimyi, M.S. Chepchurov, B.S. Chetverikov, N.A. Tabekina, E.I. Evtushenko, "The technological heredity in the manufacture of the metalpolymer form-building molds," ARPN Journal of Engineering and Applied Sciences, vol. 11(20), p. 12302-12310, 2016.

[10] T.V. Anikanova, S.M. Rakhimbaev, A.S. Pogromsky. "Influence of thermal boundary layer on the thermal conductivity of porous and granular materials," Bulletin of the Belgorod State Technological University. VG Shukhov, vol. 4, pp. 42-46, 2015. 